\title{
The Journal Talks with 2012 TMS President Wolfgang Schneider
}

TMS President Wolfgang Schneider will complete his term as president of the society at the TMS 2013 Annual Meeting \& Exhibition in March. Schneider is head of the research and development center of Hydro Aluminum Rolled Products Business in Bonn, Germany, and is also a professor of metallurgy at the Technical University of Berlin. A member of TMS since 1996, he has been active in the Light Metals Division, including the Aluminum Committee, Aluminum Processing Committee, and Energy Committee. As Schneider neared the end of his term, JOM invited him to reminisce about the challenges and accomplishments of his year as president.

$Q$. At the start of your term as president you had a list of goals you'd hoped to achieve. Which of your goals did you achieve? Were there any disappointments along the way?

A. One goal, which I saw as high priority, and also a major challenge, was to optimize the structure of the technical divisions. After extensive discussions and group work with representatives of the divisions, as well as TMS staff, several recommendations were presented to the Board of Directors. These included revision of committee scope and mission statements, and an update to the division council structure. These recommendations are now being discussed in the divisions, laying the groundwork for eventual implementation. Although some changes are imminent, I personally had hoped that we could have been brave enough to work on a more fundamental change of the division structure.

Another priority was improving

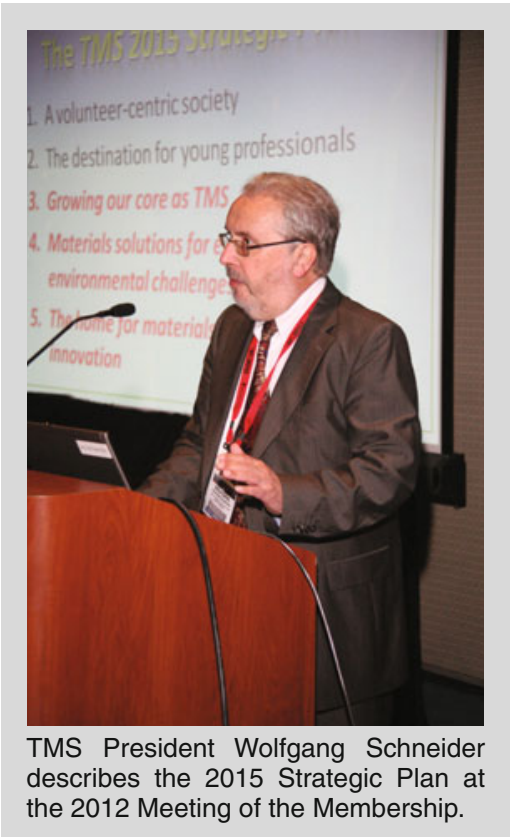

the society's continuing education program. After extensive investigation and discussion, an ad hoc committee was formed to assess the continuing education program and to make recommendations that will lead to robust growth. These recommendations will be presented at the March 2013 Board of Directors meeting. I'm optimistic that the result will be an expansion of the valuable services offered by TMS, which will contribute to the society's future growth.

Finally, making the work of the Board more efficient and improving transparency for TMS members was a goal toward which we have made good progress. I am very satisfied that in the past year the board meetings were much more focused on technical topics than on administrative topics. A report on progress made toward the goals of the strategic plan, for example, is now a standing board agenda item. And, with the introduction of a summary report of the board meetings in JOM, TMS members are better informed of that progress, as well as other board initiatives.

Q.Did your years of experience working in industry impact your approach to leading TMS? If so, how?

A. Working for more than 30 years in industry R\&D has led me to focus my attention more on technical topics than on administrative questions. Working in industry, you are always under pressure to achieve results. I believe this has influenced my approach to running Board of Directors meetings, and on a broader scale, my views on workshops and how to achieve progress.

Q.TMS began working toward fulfilling the goals of the new, 2015 strategic plan in the last year. Where did you see the most progress in that area?

A. I think significant progress has been achieved toward all goals of the strategic plan, but, in particular, the Materials and Manufacturing Innovation area has many highlights to report. To these belong, e.g., the ICME Implementation Study, the upcoming Second World Congress on ICME, and the debut of the new open access journal Integrating Materials and Manufacturing Innovation. Also worth mentioning are the extensive activities under way to sustain and grow the "Core" of TMS. Following an intensive study, an ad hoc advisory group recommended specific development opportunities, which were the subject of lively discussion at the board meeting during 


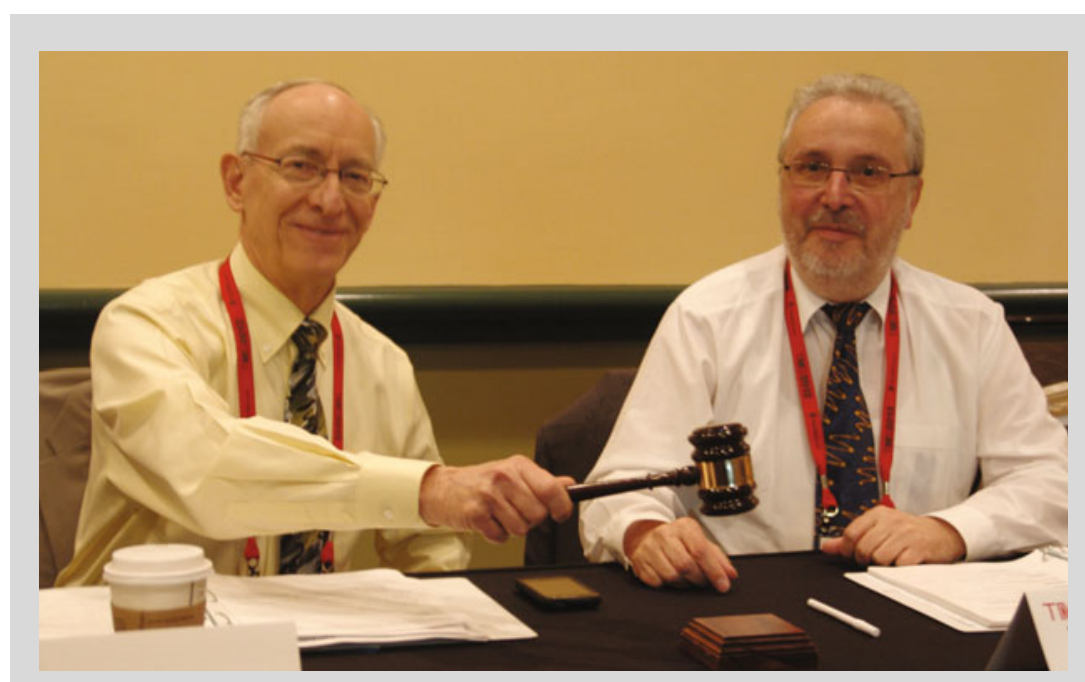

Past President Garry Warren, left, transfers the gavel to Wolfgang Schneider to begin his term of office.

the Materials Science \& Technology 2012 conference. Work is continuing toward that goal as well as the remaining three goals, which focus on materials solutions for energy and environment, and, in service to members, improved attention to volunteerism in TMS and becoming the destination society for young professionals.

Q. You were the society's first president from outside of North America. How did your international experience affect your presidency? Were there logistical difficulties, such as communicating with the headquarters office in Pennsylvania?

A. First, I have to say it is a great honor to have served as president of TMS, and especially, as the first president from beyond the North American continent.

As an international member I have tried to share my experiences and knowledge of professional society activities in Germany, which are quite different from those of U.S.-based societies. In German societies a major focus is on the continuing education of professionals in cooperation with universities and industry, a model that is successful and very well accepted. Sharing this experience with TMS for the potential improvement of TMS's approach to continuing education was one of the goals of my presidential term. And because this is a complex component of TMS's activities, I had to learn a lot before I was able to fulfill my role as TMS president. Here, my former time on the Board was very helpful.

Although I am located in Germany, the communication with the headquarters office in Pennsylvania was very easy and effective using modern communication tools. My distance from the headquarters office did not pose any disadvantage.

Q. You faced an unexpected challenge this past year with the resignation of Executive Director Warren Hunt. How did that transition affect your work as president?

A. The transition went very smoothly and did not affect my work as president. The major reason for this outcome is that excellent succession planning was done by former Executive Director Warren Hunt. Promoting former Deputy Executive Director Jim Robinson into this position was the optimal solution for TMS for immediate business continuity as well as for the long-term leadership of society operations.

Q. TMS took on a stronger role in advocacy this past year, joining with other professional societies to defend the need for investment in basic research and travel to conferences such as the TMS annual meeting. Are you satisfied with the cooperative efforts to date? Is there more that societies need to do to convince policymakers of the value of these investments, even in difficult economic times?
A. These initiatives, especially those that involved cooperation with other societies, were fairly effective and showed some first successes, as seen in the Materials Genome Initiative activities. But these advocacy endeavors should be continued to ensure that government decision-makers are aware of the impact of their decisions, and the benefits of investing in basic research.

Q. What do you see as the most important challenge facing MSE today? How can professional societies resolve that issue?

A. From my perspective as an R\&D person in the materials community, Integrated Computational Materials Engineering (ICME) is becoming increasingly important. In the long term, ICME approaches will dominate development activities to cut time and costs. TMS, with its ICME-related activities both current and planned, is actually at the forefront of this development and can play an important role in the future in sharing and generating knowledge.

Future R\&D work will take place worldwide more and more in "cluster organizations" consisting of industry and academia. For these organizations, networking is essential. Here, TMS can be very active and helpful as an information provider, especially through the society's many Materials Innovation activities.

Q. What did you most enjoy about being president of TMS?

A. As president, I enjoyed meeting people from professional societies from all around the world and participating in the networking opportunities the position affords to learn and to share experiences. I also appreciated very much the cooperation of the staff of TMS in Warrendale. It was a pleasure to work with these competent and friendly people. They gave me any support I needed.

Finally, I enjoyed being a part of the strategic work of the society. I appreciated having the chance to take part in the further development of TMS, contributing my ideas, and serving the members of TMS. 